\title{
Real-time monitoring of high-power fibre-laser cutting for different types of materials
}

\author{
${ }^{1}$ Uğur Karanfil and ${ }^{2}$ Uğur Yalçin \\ ${ }^{1}$ Department of R\&D, Durmazlar, Electrical-Electronic Engineering Department, \\ Bursa Uludag University, 16059 Bursa, Turkey; \\ E-mail: ugurkaranfil@aol.com \\ 2 Electrical-Electronic Engineering Department, Bursa Uludag University, \\ 16059 Nilufer, Bursa, Turkey; E-mail: uyalcin@uludag.edu.tr
}

Received: 13.01 .2019

\begin{abstract}
Changes in gas pressure or cutting-head focus, as well as material warming can usually occur during metals processing, thus imposing insufficient quality of the resulting materials. These problems imply quality deterioration for both laser welding and laser cutting and cause the losses in terms of both time and cost. The primary aim of the present study is to solve these problems with special software. We discuss the effects of laser power, nozzle type, cutting speed and assisting-gas pressure on the quality characteristics of cut materials. Piercing and cutting processes are experimentally performed on the samples of stainless steel, aluminium and mild steel with the thicknesses 8,12 and $20 \mathrm{~mm}$, respectively. For each of these materials, we determine experimentally 'decision times' and analogvoltage thresholds corresponding to the material-surface temperature or the light intensity and then incorporate these parameters into the algorithm. The tests have demonstrated that our monitoring-based system is more successful than the standard metals-processing systems.
\end{abstract}

Keywords: materials processing, fibre lasers, laser cutting, laser piercing, cutting parameter

UDC: $621.9 .02+535.8$

\section{Introduction}

Lasers are extensively used in many scientific and technical branches such as, e.g., communications [1], medicine [2], nuclear physics [3] and materials processing [4]. Low costs of processing, high cutting speed and accuracy have stipulated a widespread use of lasers in metals processing [5]. A number of appropriate optical laser technologies have been developed from the invention of lasers in 1960s to the present days [6-8]. Metal-working industry is usually based on optically pumped solid-state lasers, photonic-crystal lasers, chemical lasers, semiconductor lasers, dye lasers, fibre lasers, and gas lasers. In particular, fibre-laser materials processing has demonstrated a rapid development in the recent years. Due to their high beam quality and easy absorption at metal surfaces, fibre lasers are expected to challenge even $\mathrm{CO}_{2}$ and Nd:YAG lasers in the field of thick-materials cutting $[9,10]$. Surface processing techniques such as marking, engraving, cutting, welding and shaping have also become highly widespread in the recent years [11]. A common feature of these techniques is that they all need a working point to be as accurate as possible [12].

In addition to short cutting times, the quality of resulting products is also highly important in the industrial laser-cutting processes. Changing the thickness of a workpiece or the type of a material causes many optical parameters to change [13]. The quality of a workpiece is determined 
by thermal and physical properties of a material, laser power and light wavelength, cutting speed, nozzle diameter and distance, types of auxiliary gas and its pressure, and a focal distance. In general, the quality of laser cuts depends on the amount of laser energy that penetrates into the material. For this reason, the thermal properties of materials also play a major role in the laser cutting and, in particular, in the quality of cutting process [14-17]. Moreover, a focus position should be adjusted with high accuracy to provide an optimal cutting quality. Finally, different types and thicknesses of materials change both the optimal focus and the laser beam intensity needed [16-18].

The cutting speed is one of the most important parameters of the above processes. It should be balanced well, depending on the laser power and the gas-flow rate. With increasing cutting speed, the strips formed at cutting edges become obvious, the dross under cutting edges accumulates and the penetration decreases. For instance, melting occurs at the cutting edges at low cutting speeds whenever oxygen is used for cutting mild steel. The resulting melt reduces the quality of cutting edges and expands a heat-affected zone.

Generally, cutting speeds are inversely proportional to the thickness of material. Moreover, the speed needs to be reduced to avoid burns in corner turns $[16,19,20]$. Nozzles ensure that the cutting gas is transported coaxially with respect to the laser beam to cutting area and adjust the gas pressure. The design of nozzles and, in particular, of mouthpieces determines the form of the cutting gas jet and thus determines the cutting quality. The diameter of the nozzle usually varies from 0.8 to $4 \mathrm{~mm}$. It is selected depending on the material type and sheet thickness [16, 19]. A number of basic principles can be formulated regarding the auxiliary gas in laser cutting. So, nitrogen removes the cut material from underneath the cutting zone without re-solidification, while oxygen enters an exothermic reaction with the material [21, 22]. Argon and helium are used in case of titanium sections, since they prevent oxidation and formation of brittle titanium nitrides $[17,19,23]$. The gas also plays an important role in promoting plasma formation in the cutting of thick materials with high-beam powers, since the gas stream protects the lens from dirt. Finally, the cutting edges are cooled by the gas flow such that the expansion of heat-affected zones is prevented $[16,19]$.

It is known that the processes of laser piercing and laser cutting are especially difficult in the industry of mild steel. In the present study, we suggest a solution that produces high-quality workpieces resulting from the above laser processing. The main principle of our system is based on monitoring the cutting and piercing procedures, and keeping the temperature of cutting sheet at an optimal level. For this reason, we install several sensors of different types, a fast programmable logic controller (PLC) and a communication line. To the best of our knowledge, no similar solution has been reported in the literature.

\section{Experimental procedures}

All of our tests were performed with a Durma HDFL 3015 laser-cutting machine. Owing to linear motors, very high acceleration $\left(30 \mathrm{~m} / \mathrm{s}^{2}\right)$, high travel speed $(200 \mathrm{~m} / \mathrm{s})$ and precise positioning tolerance $(0.03 \mathrm{~mm})$ were reached. The fibre-laser light was obtained from an IPG YLS 4000 CUT resonator. The piercing and cutting operations were performed using a Precitec cutting head with a $100 \mu \mathrm{m}$ fibre-core diameter. The corresponding optical characteristics, optical outputs and technical specifications of our devices are gathered respectively in Tables 1, 2 and 3. A lens in a high-pressure resistant automatic cutting head was protected from the particles formed during the cutting process, using a low-cost protection glass.

Ukr. J. Phys. Opt. 2019, Volume 20, Issue 2 
Table 1. Optical characteristics of our laser resonator.

\begin{tabular}{lccc}
\multicolumn{1}{c}{ Characteristics } & Minimal & Typical & Maximal \\
\hline Operation mode & & \multicolumn{2}{c}{$\mathrm{CW} /$ Randomly modulated } \\
\cline { 1 - 2 } Polarization & 4000 & & \\
\hline Nominal output power, $\mathrm{W}$ & & 10 & 105 \\
\hline Output-power tuning range, $\%$ & 1068 & 3 & 6 \\
\hline Emission wavelength, $\mathrm{nm}$ & & 50 & 100 \\
\hline Emission linewidth, $\mathrm{nm}$ & & 5 \\
\hline Switching on/off time, $\mu \mathrm{s}$ & & \pm 1 & \pm 2 \\
\hline Output-power modulation rate, $\mathrm{kHz}$ & & 0.4 & 0.5 \\
\hline Output-power instability, $\%$ & &
\end{tabular}

Table 2. Optical output of our laser resonator.

\begin{tabular}{lccc}
\hline \multicolumn{1}{c}{ Characteristics } & Minimal & Typical & Maximal \\
\hline Delivery-fibre connector & $\begin{array}{r}\text { HLC-8, QBH-compatible } \\
\text { LCA, QD-compatible }\end{array}$ \\
\hline $\begin{array}{l}\text { Beam parameter product }(86 \%), \\
\text { mm } \times \text { rad }\end{array}$ & & 2.0 & 2.2 \\
\hline Delivery-fibre length, $\mathrm{m}$ & 10 & 20 & 30 \\
\hline $\begin{array}{l}\text { Delivery-fibre bending radius, } \mathrm{mm} \\
- \text { unstressed }\end{array}$ & 100 & & \\
- stressed & 200 & & \\
\hline
\end{tabular}

Table 3. Technical specifications of our laser-cutting head.

\begin{tabular}{lc}
\hline \multicolumn{1}{c}{ Specification } & Value \\
\hline Laser wavelength, $\mathrm{nm}$ & $1030-1090$ \\
\hline Laser power, $\mathrm{W}$ & max. 6000 \\
\hline Collimation focal length, $\mathrm{mm}$ & 100 \\
\hline Focusing focal length, $\mathrm{mm}$ & $125,150,175,200$ \\
\hline External acceleration, $\mathrm{m} / \mathrm{s}^{2}$ & 45 \\
\hline Cutting-gas pressure, bar & $\operatorname{max.~25}$ \\
\hline Auxiliary-gas pressure, bar & $\max .5$ \\
\hline Cooling-gas pressure, bar & $\max .5$ \\
\hline Operating voltage, $\mathrm{V} \& \mathrm{~A}$ & $\max .24,10 \%$ \& 4 \\
\hline
\end{tabular}

The size of each plate was equal to $500 \times 200 \mathrm{~mm}^{2}$. The measurements were made at different material thicknesses (8, 12 and $20 \mathrm{~mm}$ ). A pure (99.99\%) oxygen gas and a nitrogen gas were used as auxiliary gases for the piercing and cutting operations. The focus and nozzle distances varied due to step-by-step implementation. In addition to step piercing, our records were concerned with straight, curved and corner cuts. The ranges of the parameters taken for the piercing and cutting tests are shown in Table 4.

The laser beam was carried with a standard optical-fibre cable. The appropriate polarization effects were not addressed in this study. The maximal cutting speed was set according to the condition that the workpiece to be cut could be completely separated from the whole of the plate. The quality of the edge cut and the piercing were determined by visual examination. To monitor the cutting and piercing processes, sensors with $0-10 \mathrm{~V}$ analog outputs were used. These parameters were processed using special algorithms and software in an embedded processor, in order to control the laser machine with a computer numeric control (CNC). 
Table 4. Parameters of our laser cutting and piercing processes.

\begin{tabular}{ccccc}
\hline $\begin{array}{c}\text { Laser power, } \\
\mathrm{kW}\end{array}$ & $\begin{array}{c}\text { Cutting speed, } \\
\mathrm{m} / \mathrm{min}\end{array}$ & $\begin{array}{c}\text { Assistant-gas } \\
\text { pressure, bar }\end{array}$ & $\begin{array}{c}\text { Focus, } \\
\mathrm{mm}\end{array}$ & $\begin{array}{c}\text { Nozzle distance, } \\
\mathrm{mm}\end{array}$ \\
\hline \multicolumn{5}{c}{$20 \mathrm{~mm}$ mild steel } \\
\hline $2.1 \sim 4.0$ & $0.4 \sim 0.7$ & $0.6 \sim 0.8$ & $-6 \sim 2$ & $2.8 \sim 15.0$ \\
\hline \multicolumn{5}{c}{$12 \mathrm{~mm}$ aluminium } \\
\hline $2.0 \sim 4.0$ & $0.4 \sim 0.7$ & $12 \sim 15$ & $-4.8 \sim-2.8$ \\
\hline $3.5 \sim 4.0$ & $0.3 \sim 1.6$ & $8 \mathrm{~mm}$ stainless steel \\
\hline
\end{tabular}

\section{Principles of our system}

The main operating principle of the system suggested by us is based on controlling the temperature or the light intensity on the plate via infrared or visible light sensors. The operation of the piercingmonitoring system is explained in Fig. 1a.
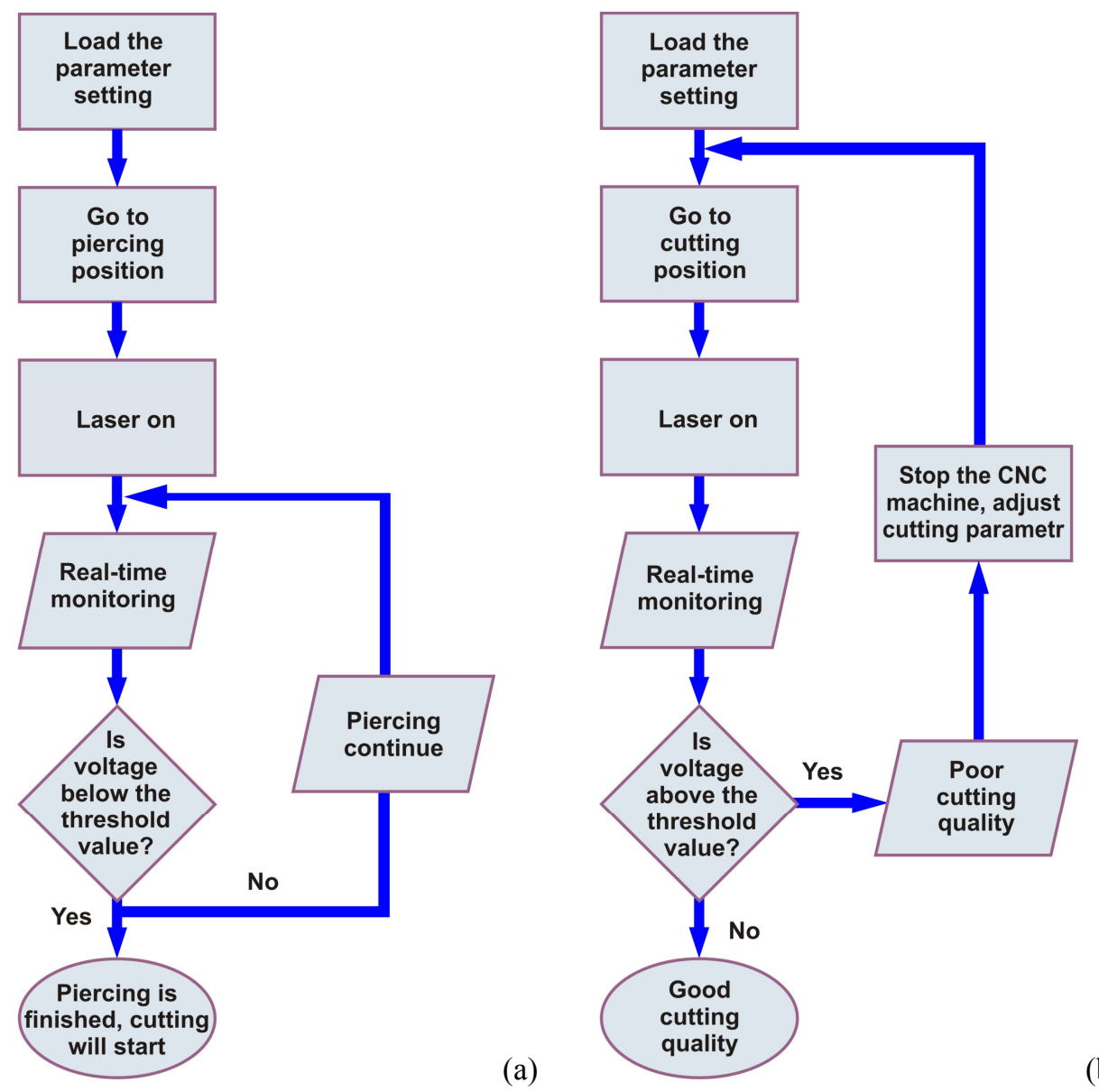

Fig. 1. Algorithms used for monitoring piercing (a) and cutting (b) processes.

First, the optical characteristics of the material to be processed are loaded into the machine. The data includes a number of parameters such as the focal length, the cutting gas and its pressure, the nozzle distance, and the piercing area. The machine incorporates these parameters by setting them in the PLC. In addition, we determine the threshold values that correspond to the materialsurface temperature or the light intensity from the earlier measurements and load these thresholds 
into a tracking system. The piercing and cutting operations are notably different in the laser technology. The piercing works step by step. Here the head height, the focus and the laser power vary at different moments. The laser light is turned on after the initial parameters of the piercing are set in the CNC machine. When the laser is switched on, the PLC switches the sensors out of a snooze mode and puts the piercing-monitoring system into an operation mode. The tracking starts at this stage. The materials of different types and thicknesses behave differently at different laser powers applied, so that it is impossible to 'tune' the system prior to the process itself. At the beginning of the process, the threshold value loaded for a given material to be processed is compared with the value the sensors have detected and is then converted to the corresponding analog voltage. If the instantly measured value remains below the threshold for a certain time, the embedded processor recognizes that the piercing is complete and sends a signal to the machine. The CNC machine cuts off the laser beam through the PLC and becomes ready for cutting. Otherwise, the system continues the piercing unless the instantaneous analog voltage, which is continuously compared by the tracking system, does not fall below the threshold for a certain time.

The cutting-monitoring system is similar to that used for the piercing process. The most important difference between the two systems is the threshold value. To operate this system, the $\mathrm{CNC}$ machine must finish the piercing and become prepared for the cutting. Fig. $1 \mathrm{~b}$ indicates operation of the cutting-monitoring system. The following eight steps have to be distinguished.

Step I. The laser beam is turned off after the piercing is finished. The cutting parameters are now called, instead of the piercing-process parameters. The optical parameters are loaded into the machine from the database of the material under processing. As mentioned above, they include such parameters as the focal distance, the cutting speed, the cutting gas and its pressure, and the nozzle distance. In general, the situation is similar to that of the piercing process. In addition, the threshold values determined in the preliminary measurements are loaded into the tracking system at this step. Another difference of the cutting-process parameters is that the parameters for the start of the cut (lead in) are different after the start (contour) and the corner turns.

Step II. In the piercing, the position of the laser head must be higher than that in the cutting process. The system that directs the piercing process in a shot-like stepwise manner is notably close to the point where the hole is made in the cutting process, in order that the gas penetrated better into the sheet.

Step III. After setting the initial values of the cutting into the CNC machine at this stage, the laser light turns on for the first time.

Step IV. When the laser beam is turned on, the PLC takes the sensors out of the snooze mode and switches the cutting-observation system to the operating mode. Monitoring starts at this stage.

Step V. Here the instantaneously measured values are continuously compared with the threshold values, which is the same as in the piercing operation. If the instant value stays above the threshold at a given moment, the system jumps to Step VII; otherwise it proceeds to Step VI.

Step VI. Here the embedded processor does not detect any negative conditions and therefore does not intervene in the cutting, assuming that the cutting process continues normally. After the workpiece cut is completed, the CNC machine turns off the laser beam via the PLC. It also switches the sensors and the system to the snooze mode.

Step VII. Since the instantaneous analog voltage value remains above the threshold for a certain period of time, the system finds out that the condition is unfavourable and sends a signal indicating that a poor-quality cutting has been made by the machine.

Step VIII. When the CNC machine receives the signal of poor cutting quality, it immediately 
turns off the laser beam and stops moving its axes. The laser head lifts up from the cutting position and comes back a certain distance along the cutting path. It makes some changes in the cutting speed and the other parameters, and then goes back to Step II.

The latter process is repeated three times for a given contour. If it still detects a fault signal in the cutting process, it jumps to the other part of a sheet. The system reloads the original cutting parameters when switching between the parts and the contours. If the same problem is encountered in the other part it passes, the system stops the machine completely and warns the operator with an alarm message.

\section{Measurements and their discussion}

Different tests and measurements have been made in order to understand how the material type and the material thickness affect the characteristics of our system. The parameters used according to the material type are shown in Table 4. In this study, the surface topography is visualized with scanning electron microscope (SEM) images obtained at the TÜBİTAK Butal Laboratories.

In the plots obtained during the measurements, we show the voltage values obtained from the sensor $(0-10 \mathrm{~V})$, which correspond to the time in seconds. The sensors monitor the piercing and cutting processes completed with the fibre-coupled laser and analyze the emissions produced during the laser cutting in the visible and infrared spectral ranges. During the cutting and piercing processes, the sensors send the output signals which can be analyzed with the CNC machine. For a more detailed view and tracing of the plots, a multiplier can be used on the ordinate axis. At the last steps of the piercing process, we have attempted to select the lowest 'decision time' in order not to apply the excess laser power to the material.

The laser powers from 2 to $4 \mathrm{~kW}$ have been employed to observe the influence of the power. Fig. 2 presents the piercing and cutting plots for the case of $8 \mathrm{~mm}$ thick stainless steel as a working material. The laser power $3.5 \mathrm{~kW}$ has been applied for the piercing. This power was increased up to $4 \mathrm{~kW}$ in the cutting process.

In the case of $8 \mathrm{~mm}$ stainless steel, the piercing process consists of two steps. Here a $2.5 \mathrm{~mm}$ single nozzle is used. According to our data, $0.8 \mathrm{~V}$ is an ideal value for the piercing threshold in case of the stainless steel. The measurements show that the decision time $10 \mathrm{~ms}$ is appropriate for the system to be stable. In the cutting process, the signal has been approximately $0.5 \mathrm{~V}$. We have demonstrated in the measurements that the amplitude response of the stainless steel is high enough in the moment of deterioration. For this reason, the cutting threshold and the decision time have been set at $2.25 \mathrm{~V}$ and $10 \mathrm{~ms}$, respectively. If the standard piercing time is approximately equal to $1.0-1.5 \mathrm{~s}$ for the $8 \mathrm{~mm}$ stainless steel, the system algorithm demonstrates that the piercing time can be saved in case of workpieces with many holes.

The factors required for the high-quality laser cutting include a narrow cutting width, smooth cut surfaces, a minimal thermal damage and non-adherent dross. As mentioned in Section 1, the cutting speed is one of the most important factors of the laser cutting. In Fig. 3a we illustrate a scenario high enough cutting speed. Then the cutting quality is rather poor, and the stainless steel reacts excessively to the speed parameter. When the real-time monitoring system is activated, the corner turn becomes of a good enough quality (see Fig. 3b). Then the system with automatic speed correction makes observations after decreasing the current speed by $10 \%$, to identify the correct speed. The speed needs to be reduced in the corner turns but, if very low cutting speeds are applied, higher dross attachment and deeper grooves are observed. Fig. $3 \mathrm{~b}$ also indicates the separation points of the boundary layer that signify striation pattern. This issue will be analyzed in our future work.

Ukr. J. Phys. Opt. 2019, Volume 20, Issue 2 


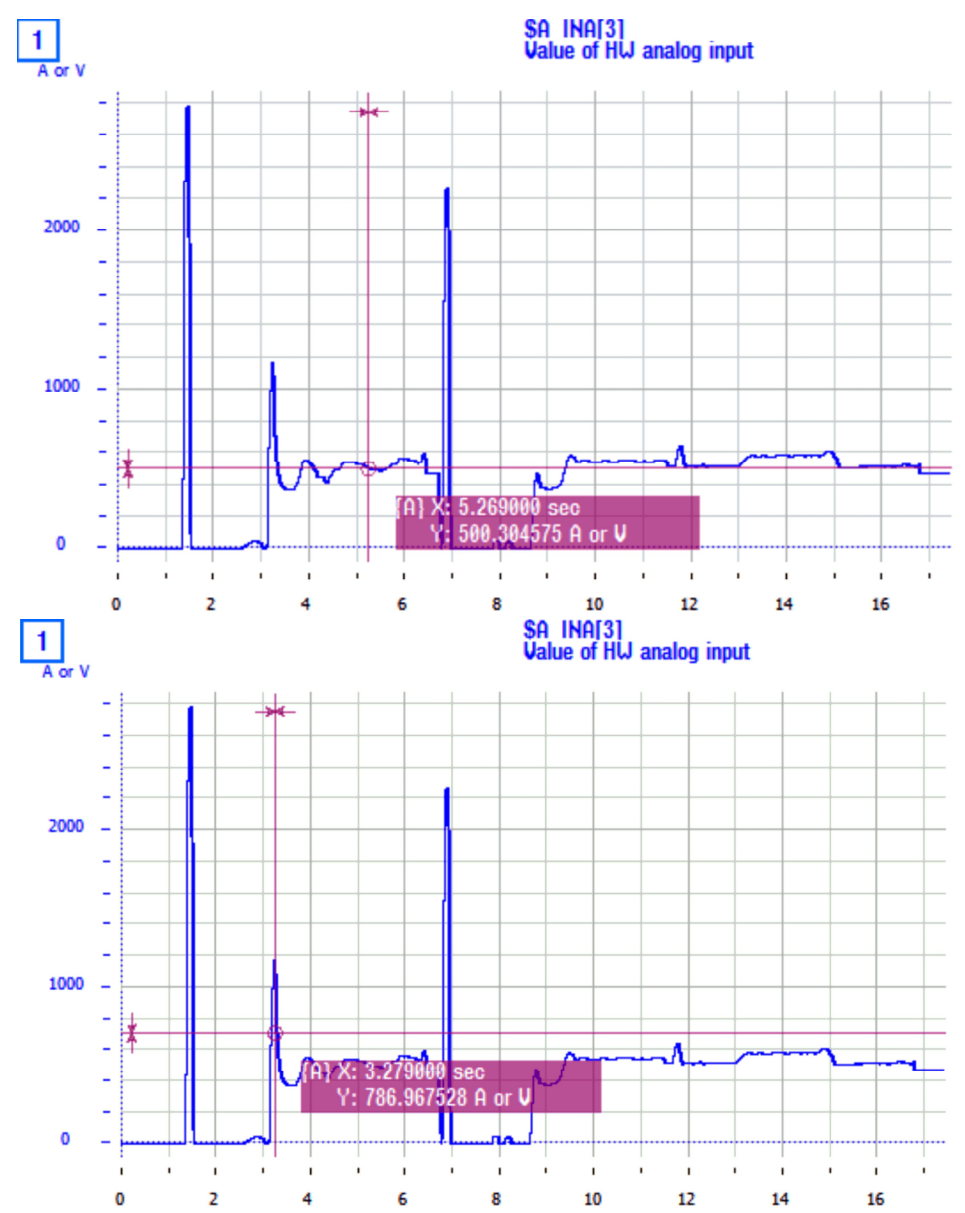

Fig. 2. Piercing and cutting parameters measured with sensor in the case of $8 \mathrm{~mm}$ stainless steel.

Fig. 4 indicates the plots measured for the case of aluminium sheet with the thickness $12 \mathrm{~mm}$. Similar to the case of stainless steel, here we prefer a $2.5 \mathrm{~mm}$ single nozzle. For the piercing, we use the laser power $2-4 \mathrm{~kW}$ in two steps (at the heights 8 and $5 \mathrm{~mm}$ ), the threshold $1.4 \mathrm{~V}$ and the decision time $30 \mathrm{~ms}$. In the cutting process, the signal amounts approximately to $0.7 \mathrm{~V}$. It has been found that the poor cut quality for aluminium is associated with the signals of high amplitude, which is the same as with the stainless steel. Therefore, it is deemed appropriate to select the threshold $3.3 \mathrm{~V}$ and the decision time $35 \mathrm{~ms}$. Next, the power $4 \mathrm{~kW}$ has been applied at the height $1 \mathrm{~mm}$ during the cutting and the nitrogen gas has been used.

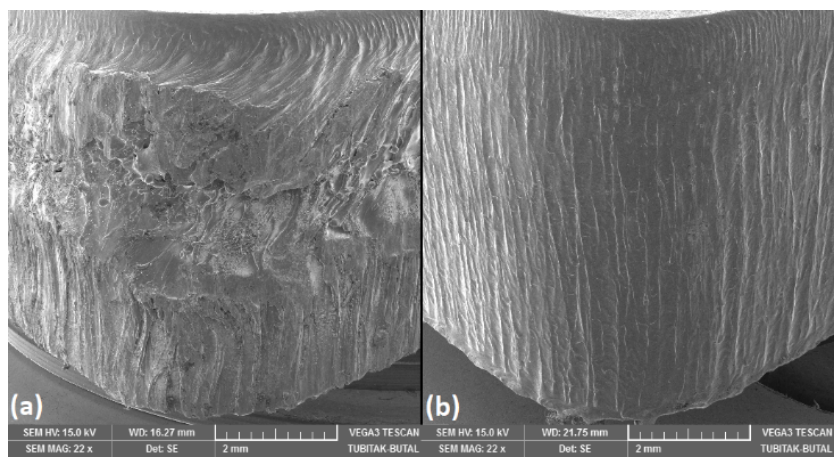

Fig. 3. SEM images of a corner section of $8 \mathrm{~mm}$ workpiece made of stainless steel: (a) poor-quality cut and (b) cut made using our real-time monitoring system. 

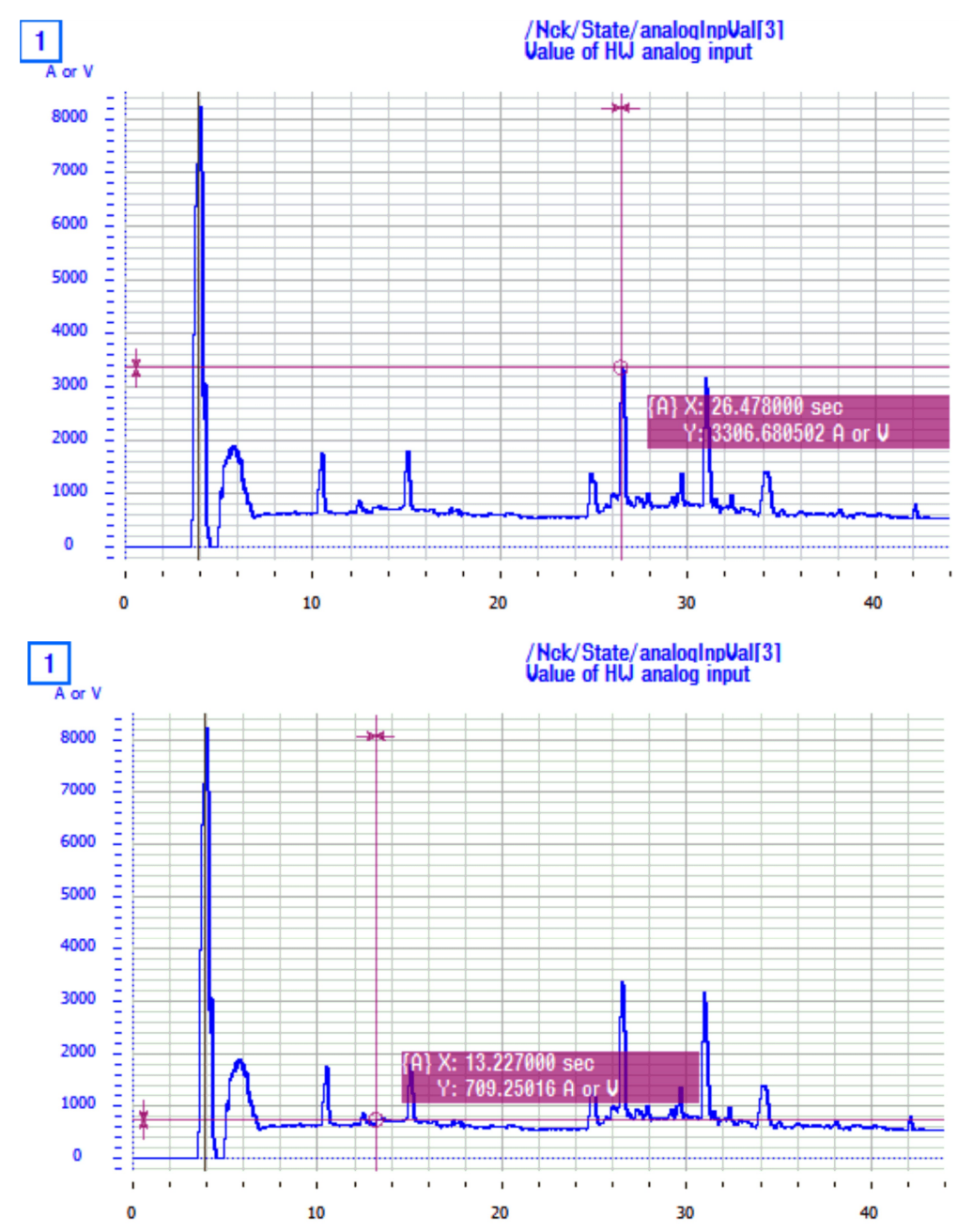

Fig. 4. Piercing and cutting parameters measured with sensor in the case of $12 \mathrm{~mm}$ aluminium.

Aluminium is much more reflective than the stainless steel so that the cutting of this material with the fibre laser can pose a potential risk. Back reflections of this type are related to laser power, surface irregularities of the sheet, lack of precise alignment with the surface normal, and a limited collection angle of the optics [24]. Note that the laser beam reflected from the flat plate can cause serious damage to the laser itself since it can be transmitted back through the optics. For this reason, we suggest a software-based protection system that measures continuously the back reflection through the sensors. In case of the resonator characterized by the optical outputs used in this study (see Table 1), the laser-power output is cut off once the critical threshold level is exceeded.

Our studies have revealed that $12 \mathrm{~mm}$ represents a limit for the aluminium thickness when the laser power is equal to $4 \mathrm{~kW}$. It produces bright lights which can be easily detected by the sensor at high speeds. In Fig. 5a, a cutting scenario with high corner-turning speed has been implemented. When the real-time monitoring system is off, the cutting quality is below the desired level. With the activation of the system, the automatic speed correction is switched on once the poor quality has been detected. Then the system reduces the cutting speed by $15 \%$ and makes it possible to obtain a smoother cutting surface and non-adherent dross (see Fig. 5b). 
In our final measurements, we have dealt with $20 \mathrm{~mm}$ thick mild steel, which is more difficult to pierce than the other materials. As seen from the marked area of Fig. 6a, the temperature at the material surface increases gradually with increasing piercing time. Excessive heating of the material surface imposes deterioration of the piercing zone and enlargement of the hole diameter. It is therefore especially important to select a correct piercing parameter in the case of thick materials.

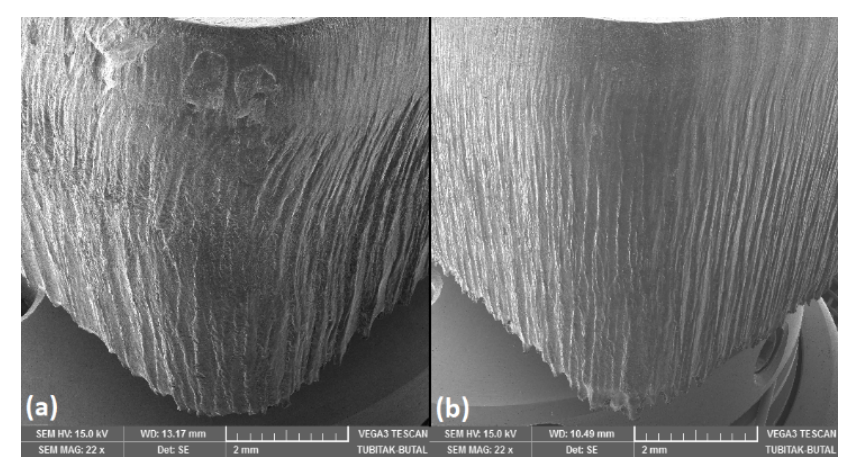

Fig. 5. SEM images of a corner section of $12 \mathrm{~mm}$ aluminium workpiece: (a) poorquality cut and (b) cut made using our real-time monitoring system.
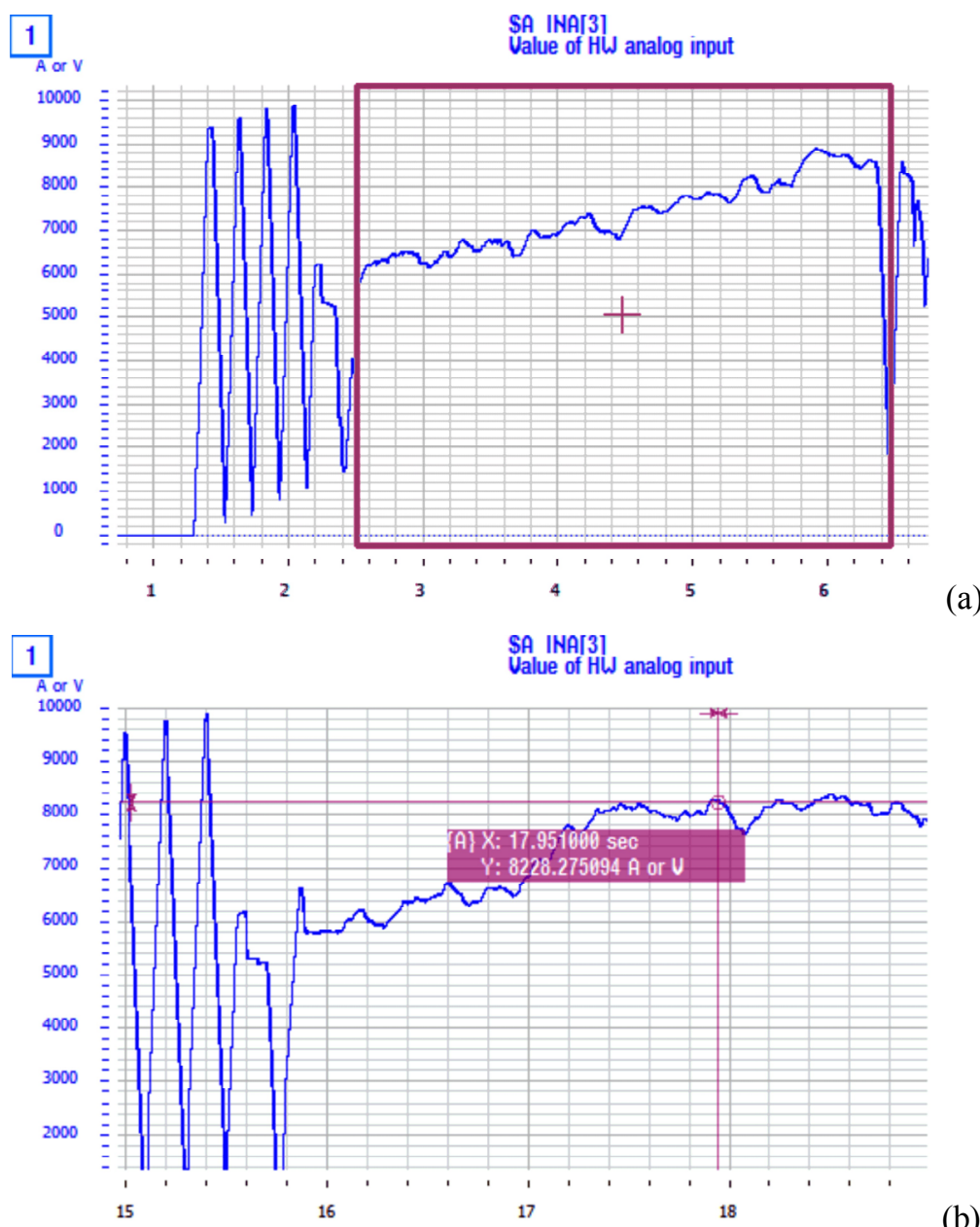

\section{(a)}

(b)

Fig. 6. (a) Piercing and cutting parameters measured with sensor in the cases of (a) $20 \mathrm{~mm}$ mild steel and (b) $20 \mathrm{~mm}$ mild steel. 
When the mild steel is dealt with, the infrared sensors are more reliable than the visible-light ones. This is because the temperature increase is more significant in an oxygenated cut made on the mild steel. In the piercing process, the laser power $4 \mathrm{~kW}$ has been applied in four steps (at the heights changing from 6 to $15 \mathrm{~mm}$ ), and 0.6 bar oxygen has been used as an assistant gas. For the testing piercing measurements, the threshold $3.7 \mathrm{~V}$ and the decision time $90 \mathrm{~ms}$ have been deemed to be appropriate. Fig. $6 \mathrm{~b}$ presents the cutting plot from the second contour of the workpiece.

When the piercing parameters obtained in the first contour are applied to the second contour, the piercing time is reduced, and the cutting process is started sooner. This process has been carried out by applying the pressure 0.65 bar and fixing the double nozzle size at $3 \mathrm{~mm}$, the laser power at $3.3 \mathrm{~kW}$ and the height above the sheet at $2.8 \mathrm{~mm}$. We have observed that the amplitude varies between 6.0 and $8.2 \mathrm{~V}$ during good cutting. The sheet remains notably hot during poor cutting and the melting is too much. As a consequence, our cutting measurements have proven that the threshold $9.5 \mathrm{~V}$ and the decision time of $25 \mathrm{~ms}$ should be chosen.

Due to its good properties and low price, mild steel is one of the steels preferred for many industrial applications. During the appropriate process, a thin layer of melt flows down and generates slow waves at the melt surface area [25]. Notice that Tani et al. [26] have explained that the dross appearing at the lower edge of kerf taper and the scratches on the cut edges depend on the melt-film properties [25].

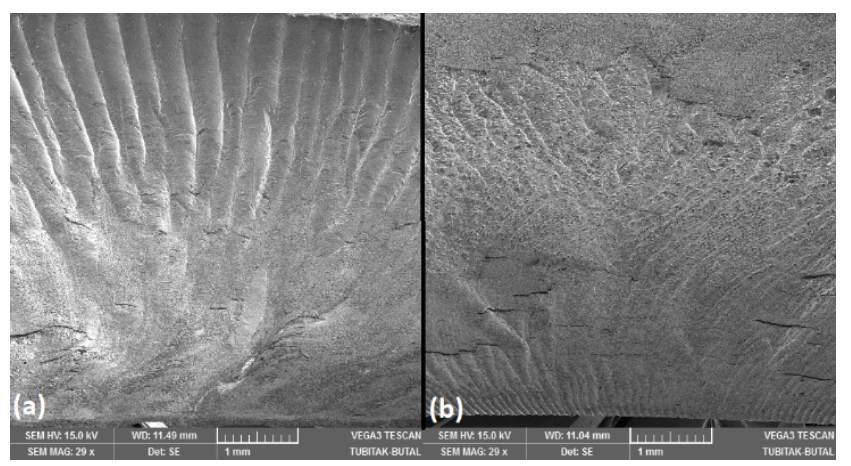

Fig. 7. SEM images of a $20 \mathrm{~mm}$ mildsteel workpiece: (a) poor-quality cut and (b) cut made using our real-time monitoring system.

In Fig. 7a we illustrate a scenario associated with a high laser power and a high speed. When our monitoring system is turned off, the amount of dross remains notably large, and the cutting quality is below the desired level. Wolfgang et al. [27] have clarified that formation of dross is related to the properties of melt film, e.g., its thickness and velocity. This outcome has also been associated with the experimental results on free viscous surface flows around the edge and separation of the melt flow from the surface [25]. After our real-time monitoring system is activated, the process interferes because the temperature is at an abnormal level. The system can distinguish between the smooth and poor cuts through its sensors. It reconsiders the cutting process by reducing the laser power and the cutting speed by $10 \%$. Fig. $7 \mathrm{~b}$ shows the SEM image of the section for which the real-time monitoring system is active.

\section{Conclusions}

The measurements performed in the present work on the fibre-laser piercing and cutting of different materials with different thicknesses have revealed that the sensor type, the piercing and cutting thresholds and the stability time change depending on the material characteristics. In our experiments and analyses, we have paid the greatest attention to such types of sheet metals which are extensively used in industry.

Ukr. J. Phys. Opt. 2019, Volume 20, Issue 2 
We have found that the analog response amplitude increases considerably with increasing laser power applied to material. It is especially typical for the mild steel. We have revealed that the response from poor cutting observed for the cases of stainless steel and aluminium is larger than that observed for the mild steel. In the presence of many factors that affect the processing of sheet metals, one cannot use the same ruling parameters to process different materials. For this reason, it is inevitable to use an intelligent monitoring system in the industrial processing machines.

According to our suggestions, the technology for observing the laser cutting interferes directly with the process being performed. It prevents the material from deteriorating during the piercing and cutting operations. In this respect, our system has the advantages in reducing sheet cost, saving time, preventing distortions caused by boiling, and preventing distortions, dross and loss of work force. Moreover, the automatic operation system recognizes in real time the events which a human cannot catch, and introduces them into the algorithm. We have revealed in our measurements and analyses that this feature can prevent unnecessary warming of the sheet metal, achieve smaller-size holes and obtain better-quality cuts, if compared with standard laser machines. Hence, the results presented in this study offer significant technological advances in the high-quality laser piercing and cutting.

\section{Acknowledgments}

A part of this work was supported by Durmazlar Makina A. Ş. (R\&D Department, Bursa, Turkey). We also thank our colleagues from Durmazlar for providing both the insight and expertise that have assisted greatly the present research.

\section{References}

1. Xianghui Yin, Rui Wang, Shaoxin Wang, Yukun Wang, Chengbin Jin, Zhaoliang Cao and Li Xuan, 2018. Evaluation of the communication quality of free-space laser communication based on the power-in-the-bucket method. Appl. Opt. 57: 573-581.

2. Serebryakov V A, Boǐko É V, Petrishchev N N and Yan A V, 2010. Medical applications of mid-IR lasers. Problems and prospects. J. Opt. Technol. 77: 6-17.

3. Izawa Y, Miyanaga N, Kawanaka J and Yamakawa K, 2008. High power lasers and their new applications. J. Opt. Soc. Korea. 12: 178-185

4. Arai A, Xu J, Sohn J and Cho G C, 2011. Applications of femtosecond fiber lasers in material processing. 12 ${ }^{\text {th }}$ European Quantum Electronics Conf. (CLEO EUROPE/EQEC), 1.

5. Karanfil U and Yalçin U, 2016. Characteristic of laser cutting observation technology and applications. In: National Conf. on Electrical, Electronics and Biomedical Eng., 2016, pp. 257-261.

6. Born $\mathrm{M}$ and Wolf E, Principles of optics, VII ${ }^{\text {th }}$ Expanded Ed. Cambridge: Cambridge University Press, (1999).

7. Sarnık M and Yalçin U, 2017. Uniform scattered fields from a perfectly conducting parabolic reflector with modified theory of physical optics. Optik. 135: 320-326.

8. Sarnık M and Yalçın U, 2016. Modified theory of physical optics and solution for scattering fields from a perfectly conducting parabolic reflector. In: IEEE Int. Conf. on Math. Methods in Electromagnetic Theory (MMET), 2016. pp. 349-352.

9. Wandera $\mathrm{C}$ and Kujanpaa V, 2010. Characterization of the melt removal rate in laser cutting of thick-section stainless steel. J. Laser Appl. 22: 62-70.

10. Sobih M, Crouse P L and Li L, 2008. Striation-free fibre laser cutting of mild steel sheets. Appl. Phys. A. 90: 171-174. 
11. Kovalenko V and Zhuk R, 2004. Systemized approach in laser industrial systems design. J. Mater. Proc. Technol. 149: 553-556.

12. Jezeršek M, Gruden V and Možina J, 2004. High-speed measurements of steel-plate deformations during laser surface processing. Opt. Express. 12: 4905-4911.

13. Fox M D, French P, Peters C, Hand D P and Duncan P J D C, 2002. Applications of optical sensing for laser cutting and drilling. Appl. Opt. 41: 4988-4995

14. Ahn D G, Byun K W and Kang M C, 2010. Thermal characteristics in the cutting of inconel 718 superalloy using CW Nd:YAG laser. J. Mater. Sci. \& Technol. 26: 362-366.

15. Lan H, Wang W, Shangguan $Y$ and Lin S, 2011. Fundamental studies on high power fiber laser cutting performance of $30 \mathrm{~mm}$ thick carbon steel plate. In: Strategic Technology (IFOST), 6th IEEE Int. Forum, 2011. pp. 6-11.

16. Urguplu M and Koksal S, 2015. The effect of laser cutting process parameters on the quality of metallic components academic platform, SITES, 868.

17. Rajendran N, An experimental and theoretical study of heat transfer effects during a lasercutting process. Iowa State University, Dissertation, (1990).

18. Anon., Facts about: laser cutting techniques, AGA Group Ltd, 4-12.

19. John C I. Laser processing of engineering materials, Elsevier-Butterwort- Heinemann, 347365 (2005).

20. Ivarson A, On the physics and chemical thermodynamics of laser cutting. Luleå tekniska universitet, Doct. Thesis, (1993).

21. Sundar M, Nath A K, Bandyopadhyay D K, Chaudhuri S P, Dey P K, Misra D, 2009. Effect of process parameters on the cutting quality in lasox cutting of mild steel. Int. J. Adv. Manufacturing Technol. 40: 865-874.

22. Ivarson A, Powell J, Kamalu J and Magnusson C, 1994. The oxidation dynamics of laser cutting of mild steel and the generation of striations on the cut edge. J. Mater. Process. Technol. 40: 359-374.

23. Gabzdyl J T, 1996. Effects of gases on laser cutting of stainless steels. ICALEO, C39-C44.

24. Dahv A, Kliner V, Bell J and Sheehan L, 2016. Fiber laser allows processing of highly reflective materials. Industrial Laser Solutions. 31: 13-14.

25. Alsoufi M S, Suker D K, Alsabban A S and Azam S, 2016. Experimental study of surface roughness and micro-hardness obtained by cutting carbon steel with abrasive WaterJet and laser beam Technologies. Amer. J. Mech. Eng. 4: 173-181.

26. Tani G, Tomesani L, Campana G and Fortunato A, 2004. Quality factors assessed by analytical modelling in laser cutting. Thin Solid Films. 453: 486-491.

27. Schulz W, Kostrykin V, Sen M N, Michel J, Petring D, Kreutz E W and Poprawedag R, 1999. Dynamics of ripple formation and melt flow in laser beam cutting. J Phys D: Appl. Phys. 32: $1219-1228$.

Uğur Karanfil and Uğur Yalçın. 2019. Real-time monitoring of high-power fibre-laser cutting for different types of materials. Ukr.J.Phys.Opt. 20: 60 - 72. doi: 10.3116/16091833/20/2/72/2019

Анотація. Зазвичай під час обробки металів мають місие зміна тиску газу або фокусу ріжучої головки, а також нагрівання матеріалу, щзо призводить до недостатньої якості отриманих матеріалів. Ці проблеми спричиняють погіршення якості лазерного зварювання i лазерного різання, а також викликають втрати часу $i$ коштів. Основна мета иього дослідження- розв'язання цих проблем за допомогою спеціального програмного забезпечення. Нами розглянуто вплив потужності лазера, типу сопла, швидкості різання $i$ 
тиску допоміжного газу на характеристики якості розрізаних матеріалів. Процеси свердління та різання здійснено експериментально на зразках з нержавіючої сталі, алюмінію і м'якої сталі відповідно з товщинами 8, 12 і 20 мм. Для кожного з ичи матеріалів експериментально визначено «часи рішення» $і$ пороги аналогової напруги, які відповідають температурі поверхні матеріалу або інтенсивності світла, а потім включено ці параметри в алгоритм. Тести продемонстрували, щзо така система моніторингу успішніша за стандартні системи обробки металів. 